\title{
Investigating the Benefits and Limitations of Cascaded Converter Topologies Used in Modular Battery Systems
}

\author{
Ahmed Fares*广 Christian Klumpner* Mark Sumner* \\ *Department of Electrical and Electronic Engineering, \\ University of Nottingham, \\ Nottingham, United Kingdom \\ National Authority for Remote Sensing and Space Sciences, \\ Cairo, Egypt \\ Email: ahmed.fares@nottingham.ac.uk,klumpner@ieee.org
}

\begin{abstract}
The Performance of battery packs is highly affected by imbalances between the series connected cells that provide the required string voltage. A modular battery implementation based on cascaded converters can have advantages over traditional centralized battery systems with addons active/passive balancing techniques. This paper investigates the use of a modular battery integrated within a cascaded converter and how the choice of the converter topology for the module influences the benefits and limitations of the modular battery system performance. Simulation results have been obtained using detailed battery model to validate the analysis.
\end{abstract}

Keywords-Battery chargers, battery management, battery equalization, Lithuim Batteries.

\section{INTRODUCTION}

$\mathrm{T}$ The parameter mismatch of battery cells connected in series in terms of internal impedances or capacities can contribute to the accelerated degradation in performance of the whole pack. The impedance mismatch of cells results in increased thermal stress for the cells with higher internal resistance that may speed up their degradation [1]. Also mismatching of the cell capacities results in over-charging or over-discharging of the cells with lower capacity.

In traditional centralized battery (TCB) systems ( Fig. 1a) , a capacity mismatching between battery cells can be addressed by using a balancing system that implements passive or active balancing techniques [2-4]. The main advantage of TCB systems is that they are simple requiring a single converter, but can have a few disadvantages such as that include poor partload efficiency and reliability as they are usually based on central bidirectional DC-DC converter rated at the full power of the battery pack to control the charge/discharge process from the DC bus. Also the TCB system is not fault tolerant as any failure in one of the battery cells or in the converter can cause overall battery system failure. Traditional cell balancing systems used with the TCB systems have disadvantages that affect the overall system performance. Firstly, they can contribute to overall system energy loss due to power dissipation in the passive elements (in case of passive balancing), or converters losses during energy redirection between battery cells (in case of active balancing). Secondly, if any particular cell reached the voltage limits during charging or discharging, the charge/discharge process for the whole string needs to be halted and balancing system will be enabled until this cell voltage reaches the recovery limit [5]. The halt time will cause the charging time to be increased and may cause loss of available energy e.g. in the case of charging from a limited availability power source such solar arrays.

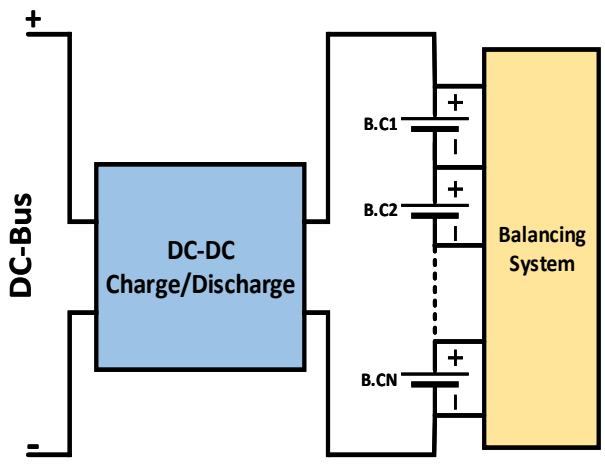

(a)

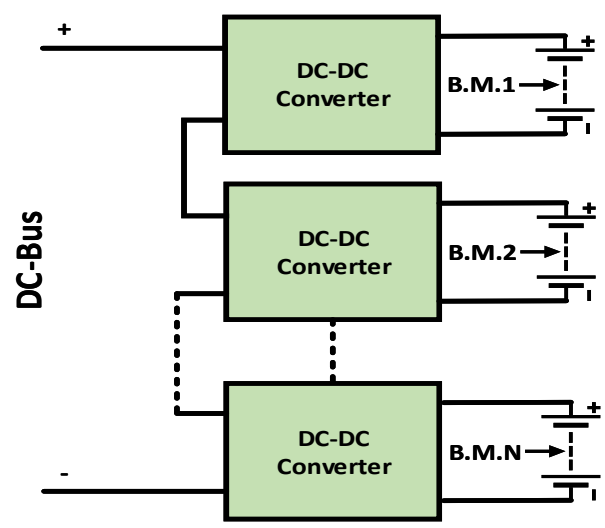

(b)

Fig. 1: Battery system configuration (a) Traditional centralized battery system (b) modular battery system. 
Typical ways to overcome halting the charge/discharge process rely on continually estimating the differences in the SoCs $(\Delta \mathrm{Q})$ and adjust the equalization currents accordingly during the charging/discharging process to prevent weak cells reaching the critical limits [6]. However it is difficult to estimate the exact SoC imbalance during operation, especially for batteries with a chemistry that results in a flat voltage vs SoC relationship such as $\mathrm{LiFePO}_{4}$ batteries [7]. An additional limitation of TCB systems is that they cannot balance the thermal stress among cells with mismatched impedances.

The modular battery system (MBS) based on cascaded converters as shown in

Fig. 1b has been introduced recently [8-12] for different applications including second life battery based systems where significant imbalances are expected. The MBS can provide advantages in controlling each battery module separately based on its SoC to ensure energy balancing. It also can provide fault tolerance as faulty cells will affect the performance of the corresponding module only which and these can be bypassed if needed, with the other healthier modules continuing to provide power. This paper investigates two different converter topologies that can be used with MBS, and describes the benefits and limitations that these topologies can add to the overall system performance.

\section{ANALYSING THE CHARACTERISTICS OF THE CASCADED CONVERTER TOPOLOGIES}

A modular battery system with a cascaded converter architecture is shown in Fig. 2. The system battery consists of " $n$ " battery modules connected in cascade to a DC bus via individual DC/DC converters. Independent on the type of the interface converter, the current of battery module " $k$ " can be defined based on the power balance equation of the converter as (1) whilst the voltage of the DC bus consists of the sum of the output voltages of the module converters (2):

$$
\begin{gathered}
I_{\text {batt.k }}=\frac{V c_{k}}{V_{\text {batt.k }}} I_{b u s} \\
V_{b u s}=\sum_{k=1}^{n} V c_{k}
\end{gathered}
$$

Based on (1) the current of each battery module can be individually controlled by controlling its interface converter. A system controller estimates the SoC and monitors the state of health SoH for each battery module based on a battery model and measured currents and voltages. Using the modules SoC and $\mathrm{SoH}$, the system controller decides the power share of each module by setting the reference current for each battery module: the converters are then controlled to follow these references which ensures the desired power sharing.

If the cascaded structure is used to deliver a constant DC bus voltage independent of load conditions, any derating of battery module current will cause a derating of the power injected which will cause an imbalance in the DC bus voltage unless this is compensated by the power/voltage injected by the other modules. This paper will investigate how this imbalance caused by an aged battery module is compensated and the limitations that exist. Two converter topologies that require the same number of semiconductor devices are investigated, namely the half bridge inverter connected in 1) voltage stepdown (buck) mode and 2) in voltage step-up (boost) mode.

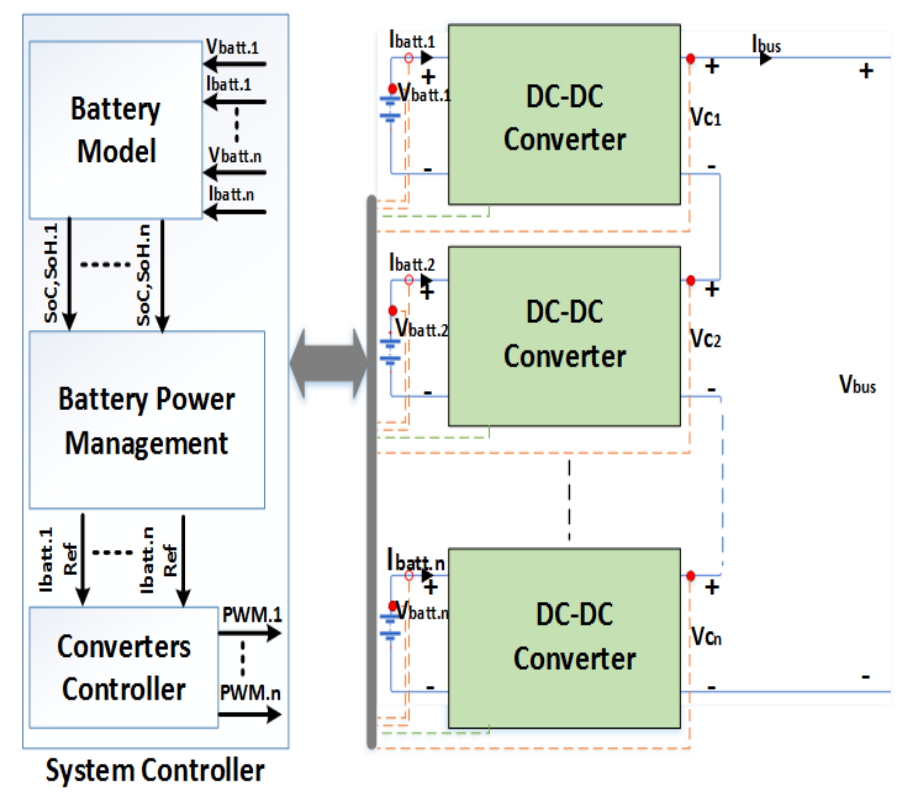

Fig. 2: MBS with cascaded converter architecture

\section{A. Using the step-down converter topology}

The cascaded topology seen in Fig. 3 is built with a series connection of the low-voltage side of the converters, while the battery modules are individually placed on the high-voltage side of each converter. This means that the voltage that each module contributes to the total bus voltage is always smaller or equal to the battery module voltage which means that if one of the modules has a weak cells that cannot handle the load current during load peaks (high power pulses), the current can be decreased to a safe level for this specific module and this can be considered as an advantage for this topology. However decreasing the current will decrease the voltage contribution of this module to the bus voltage which will alter the bus voltage unless having a redundant module to compensate for this disturbance which can be consider as a limitation for this topology.

It can be noticed that the topology can be further improved by adopting interleaved modulation of the series connected converters and using a single inductance for the whole string instead of a distributed LC on the DC bus side but the control of the string current becomes more complex in terms of intellectual challenge although simplifications in terms of hardware are clear: the individual output capacitor voltage loops as well as the cell output current and voltage transducers will no longer be needed. 
During the discharge cycle of the battery, the converters are working in buck mode with the battery modules connected to their inputs and the capacitors connected to the outputs. The capacitor voltage $\mathrm{Vc}_{\mathrm{K}}$ for converter " $k$ " can be determined as:

$$
V c_{k}=D_{k} * V_{b a t t . k}
$$

Substituting (3) into (1):

$$
I_{b a t t . k}=D_{k} * I_{b u s}
$$

During the charging cycle of the battery, the converters are working in boost mode with the capacitors connected to their inputs and battery modules connected to their outputs, capacitor voltage $\mathrm{Vc}_{\mathrm{K}}$ for converter " $k$ " can be determined as:

$$
V_{c_{k}}=\left(1-D_{k}\right) * V_{\text {batt.k }}
$$

Substituting (5) into (1) yields:

$$
I_{b a t t . k}=\left(1-D_{k}\right) * I_{b u s}
$$

Based on (4) and (6), the current of each battery module can be controlled separately by the corresponding converter duty ratio $D k$. The module current based on this topology is less than or equal to the bus current.

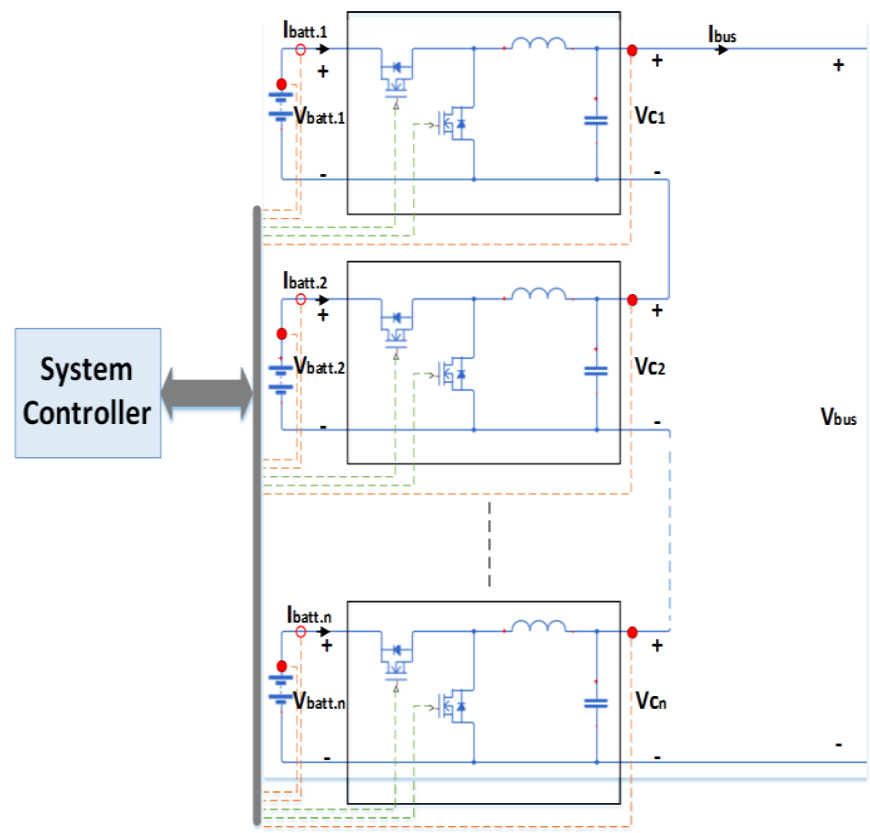

Fig. 3: Step-down converter based cascaded topology

Within this topology, the battery management controller sets the current for each module to a value between zero and $\mathrm{I}_{\mathrm{bus}}$ based on the module SoC relative to the average SoC among modules, to ensure energy balancing of all modules, or based on the module internal impedance, to ensure the thermal balancing of the modules, depending on the operating conditions. Decreasing the current of some modules will result in decreasing the output voltage of the corresponding converters and consequently, of the overall bus voltage. This can be considered as a disadvantage of this topology and this variation in bus voltage should be taken into account when deciding the number of modules in a string.

\section{B. Using the step-up converter topology}

The cascaded boost topology showing Fig.4 consists of a series connection of the high-voltage side of the half bridge converters, while connecting the battery modules to the lowvoltage side of the converters. This means that the voltage that each module contributes to the bus voltage is always larger or equal to the battery module voltage. If one of the battery modules has a weak/damaged cell that cannot handle the load currents during high power pulses, a complete isolation for this module during these periods can be achieved by means of having an additional separation switch in series with the battery module which then enables a bypass of the module by closing both switches in the converter (shoot-through state). As this topology cannot lower the current of the battery module below the load current "I bus " which can be considered as a limitation for this topology.

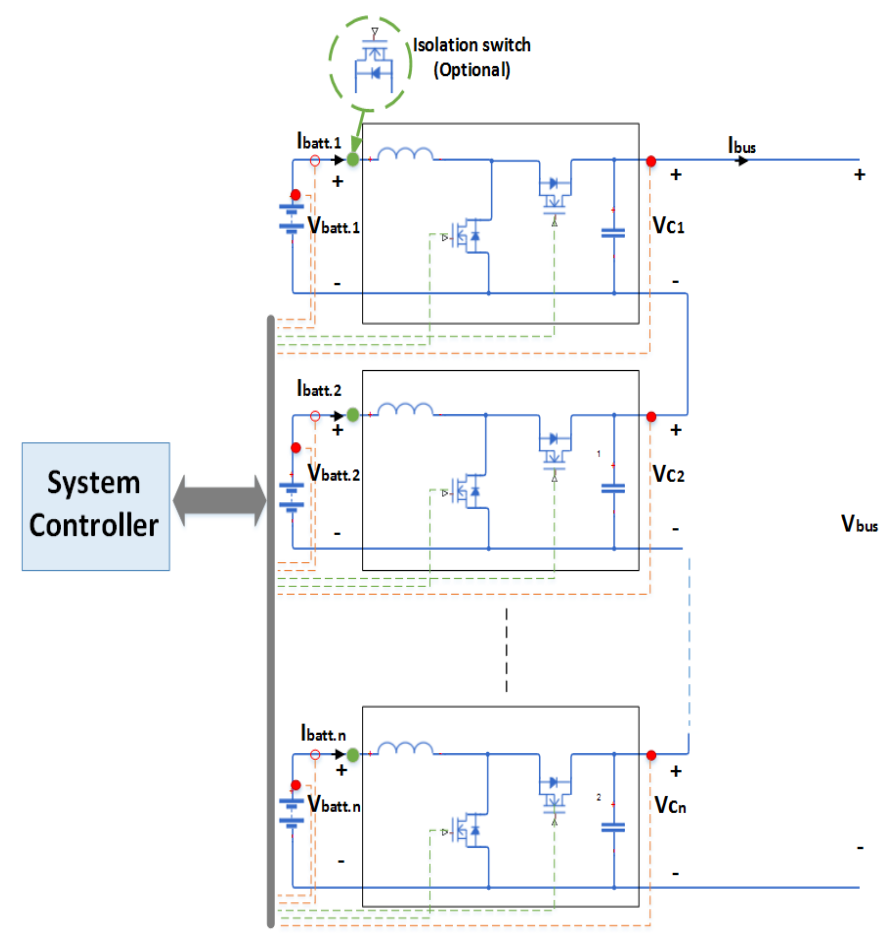

Fig.4: Step-up converter based cascaded topology

However the bus voltage can be maintained by compensating the voltage of the bypassed module by other modules as this topology allows the module voltage to be higher than battery module voltage which is a benefit for this topology.

During the discharge cycle of the battery, the converters are working in boost mode with the battery modules connected to 
the input inductors and the capacitors connected to the outputs. The capacitor voltage $\mathrm{Vc}_{\mathrm{k}}$ for converter " $k$ " is:

$$
V c_{k}=\frac{1}{\left(1-D_{k}\right)} V_{b a t t . k}
$$

Substituting (7) into (1):

$$
I_{\text {batt.k }}=\frac{1}{\left(1-D_{k}\right)} I_{b u s}
$$

During the charging cycle of the battery, the converters are working in buck mode with the capacitors connected to their inputs and battery modules connected to the output inductors. The capacitor voltage $\mathrm{Vc}_{\mathrm{k}}$ for the converter " $\mathrm{k}$ " is:

$$
V c_{k}=\frac{V_{\text {batt.k }}}{D_{k}}
$$

Substituting (9) into (1) yields:

$$
I_{b a t t . k}=\frac{I_{b u s}}{D_{k}}
$$

Based on (8) and (10), the current of each battery module can be controlled separately by the converter duty ratio $\mathrm{D}$, and the module current based on this topology is greater than or equal to the bus current. Similar to the control of the buck topology, the battery management controller for this topology sets the current for each module which ensures energy or thermal balancing of the battery modules.

\section{Comparing the two converter topologies}

In order to assess the cost for implementing the two modular converter topologies, the installed power in the switches is used:

$$
P_{i s w}=N_{M} * N d_{M} * V_{p k} * I_{p k}
$$

Where $\mathrm{N}_{\mathrm{M}}$ is the number of modules, $\mathrm{Nd}_{\mathrm{M}}$ is number of switches per Module (in our case both have two switches), $\mathrm{V}_{\mathrm{pk}}$ is the maximum voltage of the voltage source side (the battery module fully charged voltage for the buck/step down topology or the fraction of the bus voltage for the boost/step down) and $\mathrm{I}_{\mathrm{pk}}$ is the peak current on the inductor side for both topologies.

It can be noted that even though the boost/step up converter will result in smaller number of modules (assuming the battery modules have same voltage), the actual voltage stress will be higher $\left(\mathrm{V}_{\text {batt }} \mathrm{x} \mathrm{k}_{\text {boost }}\right)$. The other aspect is that the inductor current is equal to the bus current for the buck/step down arrangement whilst for the boost, the inductor current is the battery module current which is larger $\left(\mathrm{I}_{\text {bus }} \mathrm{x} \mathrm{k}_{\text {boost }}\right)$ than the bus current (assuming the two topologies feed a voltage bus of identical level). This means the installed power in the switches for the two topologies will tend to be fairly similar as long as $\mathrm{N}_{\mathrm{M}}$ buck $/ \mathrm{N}_{\mathrm{M}}$ boost $=\mathrm{k}_{\text {boost }}{ }^{2}$ which assumes the buck/step down converter is operating very close to unity voltage transfer ratio (Duty $=1$ ) and this may in fact be the case when the battery system operates near discharged conditions (where battery voltage is the minimum and the current reaches a maximum for a given power level).

A summary of the operating range for both topologies is listed in TABLE 1 where $V_{\text {pack }}$ is the overall battery voltage when all modules are connected together in series.

TABLE 1: OPERATION RANGE FOR CONVERTER TOPOLOGIES

\begin{tabular}{|c|c|c|c|}
\hline Topology & $\begin{array}{c}\text { Battery Module } \\
\text { Current }\end{array}$ & $\begin{array}{c}\text { Converter O/P } \\
\text { Voltage }\end{array}$ & Bus Voltage \\
\hline Step-down & $\mathrm{I}_{\text {batt.k }} \leq \mathrm{I}_{\text {bus }}$ & $\mathrm{V}_{. \mathrm{k}} \leq \mathrm{V}_{\text {batt.k }}$ & $\mathrm{V}_{\text {bus }} \leq \mathrm{V}_{\text {pack }}$ \\
\hline Step-up & $\mathrm{I}_{\text {batt.k }} \geq \mathrm{I}_{\text {bus }}$ & $\mathrm{V}_{. \mathrm{k}} \geq \mathrm{V}_{\text {batt.k }}$ & $\mathrm{V}_{\text {bus }} \geq \mathrm{V}_{\text {pack }}$ \\
\hline
\end{tabular}

\section{BATTERY MODEL}

In order to evaluate the performance of the modular battery system implemented using the buck or boost topology, a detailed battery model has been built based on the methodology proposed in [13]. The purpose of the detailed model is to determine the internal power losses inside the battery accurately as a strong indication of its internal temperature.

The model used is a third order equivalent circuit model (ECM) (Fig. 5) with model parameters identified at different states of charge (SoCs) for a $\mathrm{LiFePO}_{4}(3.6 \mathrm{~V} 8 \mathrm{~A})$ battery cell based on data from a battery electrochemical impedance spectroscopy (EIS) test. This modeling methodology was shown to provide a good accuracy of energy loss estimation with errors of $2-4 \%$ as reported in [13].

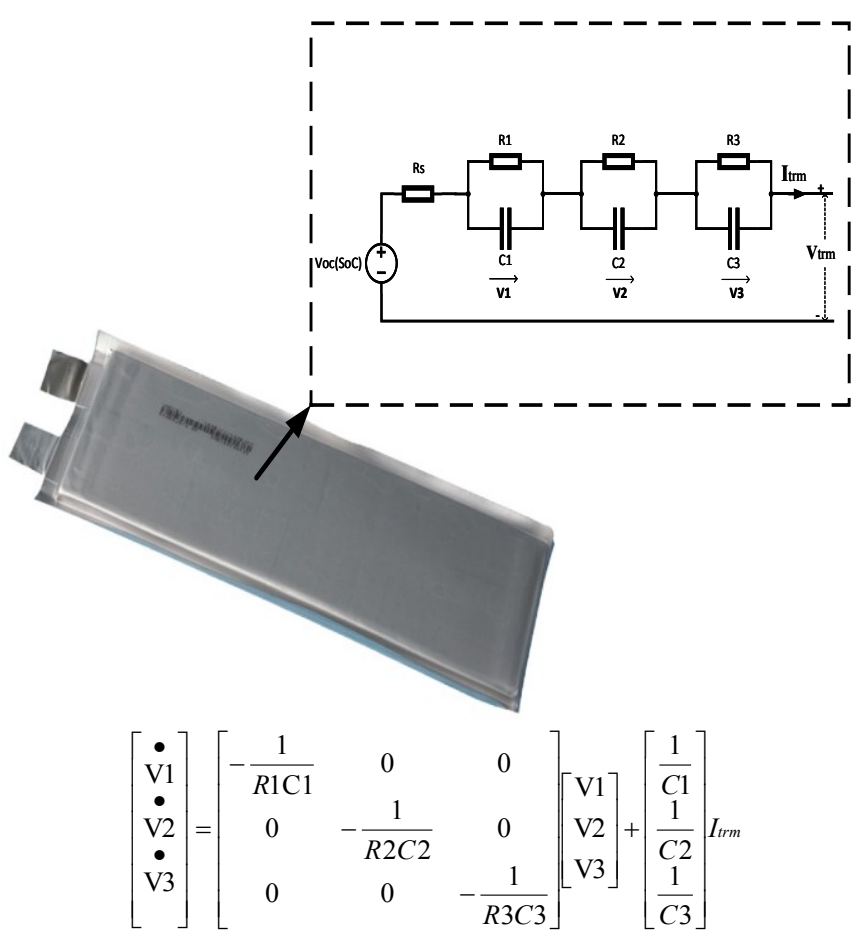

Fig. 5: 3rd Order ECM for a 3.6V 8A LiFePO4 battery cell 
The battery modules are built as a group of cells connected in series. To simplify the simulation, the cells within one module are assumed to have the same capacity and internal impedance, however the SoCs and internal impedances in different modules can take different values.

Three battery modules will be considered with two series cells per each module: module 1 and module 3 have the same capacity and internal impedance; Module 2 has a lower capacity (10\% lower) and a $25 \%$ higher internal impedance which is consistent with the expected state of a weak module. During the simulation, the SoCs were estimated based on the "Coulomb Counting" method, and the $10 \%$ capacity difference was represented by including a $10 \%$ bias in the initial SoC that was given initially to the controller.

In a real application, the system controller will be responsible for determining the actual capacities and internal impedances for all cells: then each module will then be regulated based on the weakest cell among its cells.

\section{SIMULATION RESUlTS AND DisCUSSION}

During the charging process in a traditional centralized battery (TCB) system, once one cell of the string reaches its full SoC, the charging of the whole string needs to be paused until the balancing system, which typically has a lower current rating than the main string current, catches up and removes the cells voltage imbalance after which can the charging continue. This can be seen in Fig. 6 which shows the simulation of the charging process for a string of 6 series connected cells. At $\mathrm{t}=1400 \mathrm{~s}$, cell 6 which is the weakest in terms of capacity, reached $100 \%$ SOC and continuing the charging would damage it. For this reason, charging stops and the balancing circuit operates alone to reduce the SOC imbalance.
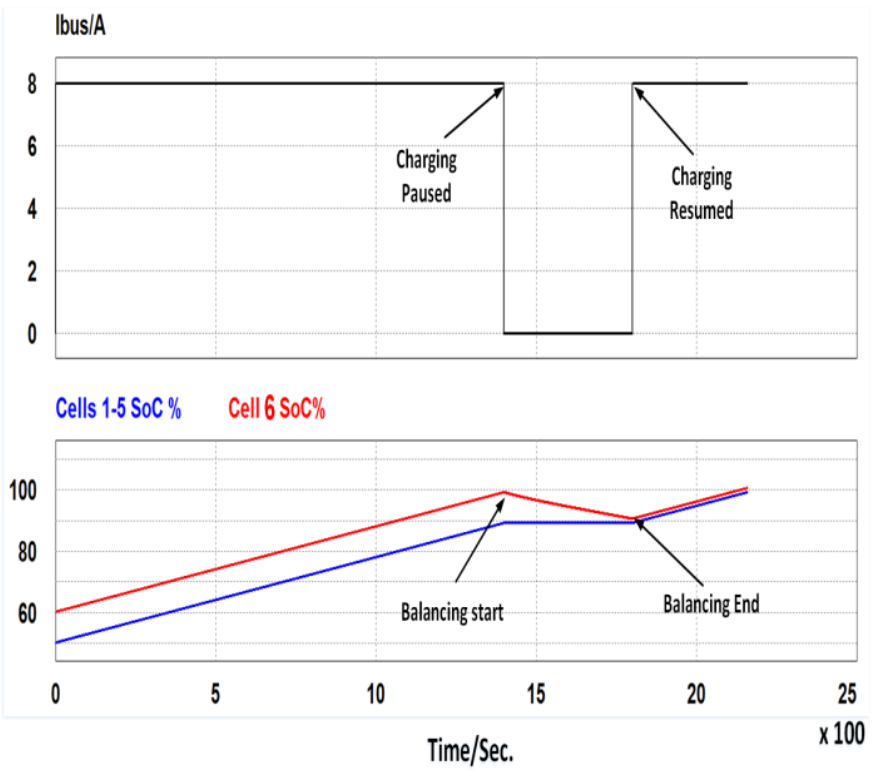

Fig. 6: Charging process with TCB system

At $\mathrm{t}=1800 \mathrm{~s}$, the SOC imbalance is canceled and the charging resumes. It is clear this practice is not acceptable for processes that require fast charging (e.g. electric vehicles) or for charging from a limited availability power source such as solar or wind, as the pause of battery charging will cause a loss of available energy during periods of resource.

Internal impedance mismatching of the cells causes different power losses and temperatures within cells as can be seen in Fig. 7. The power loss in cell 6 is higher compared to the other cells (1-5) as its internal resistance is $25 \%$ higher. The difference in power losses becomes more obvious and effective when the battery string is loaded with a high current pulse that starts at $\mathrm{t}=300 \mathrm{~s}$ with amplitude of $24 \mathrm{~A}$ (the negative sign refers to discharging). The power losses in cells (1-5) reached 20 watt maximum whilst the power losses in cell 6 reached 25 watt which is $25 \%$ more than other cells as expected. As the temperature has a strong effect in battery degradation, cell 6 supposed to experience an accelerated degradation i.e., (higher temperature causes more degradation which results in increasing cell resistance that causes higher temperatures) that will cause it to be more worth.

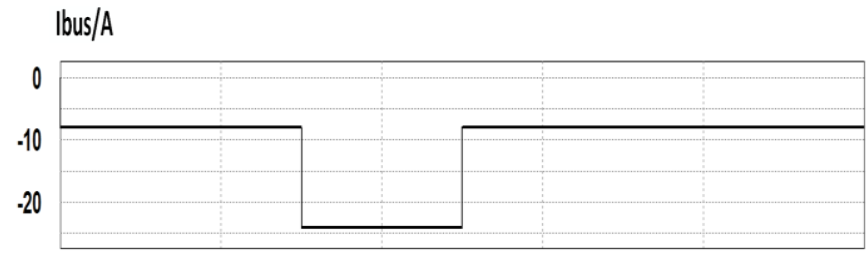

\section{Power losses/ W}
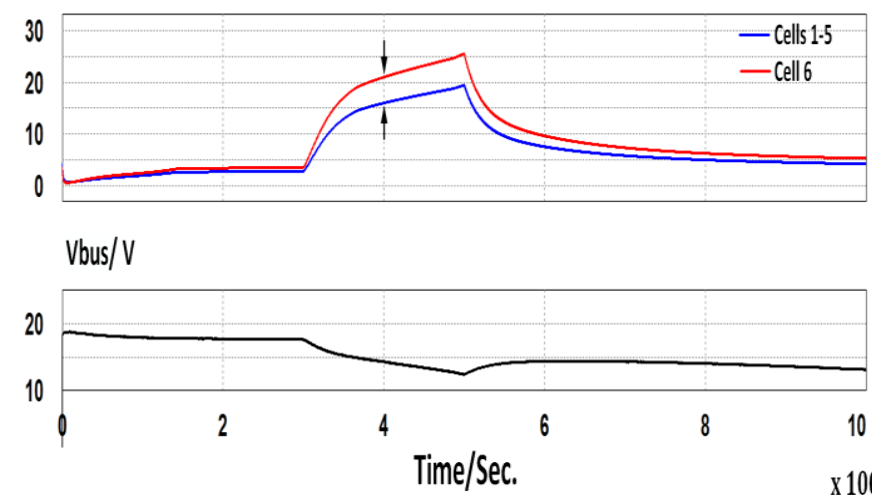

Fig. 7: Imbalance of power losses for the string of cells in (TCB) system.

With the modular battery system (MBS) based on the stepdown cascaded topology, the capacity imbalance can be compensated by allocating a lower proportion of the power to modules with lower capacity during the charge/discharge operation by controlling the module currents so that all reach their full SoC at the same time. As can be seen in Fig. 8, during the charging process, the controller sets the current of module 2 to be $5.8 \mathrm{~A}$ as this module has $10 \%$ less capacity compared to the other modules ( 1 and 3 ) whilst the current for the other two modules is set to $8 \mathrm{~A}$. Once the differences between the SoCs of the three modules is significantly reduced $(t=1100 \mathrm{~s})$, the controller increases the current for module 2 to $6.5 \mathrm{~A}$ in order to reach $100 \% \mathrm{SoC}$ at the same time $(\mathrm{t}=1400 \mathrm{~s})$ 
as the other modules. It can be observed that the MBS can remove the need for pausing the charge process as happens with the TCB system.

Current/A
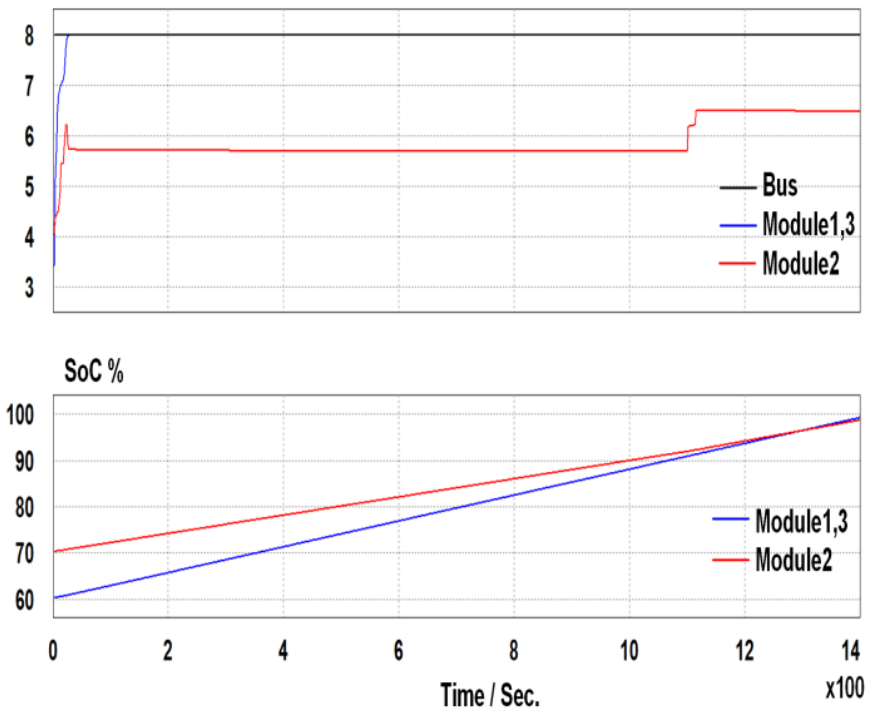

Fig. 8: Charging process with cascaded buck topology

Thermal balancing between cells can also be achieved using the MBS in the buck topology by controlling the battery modules currents according to the cells' internal impedances especially during high power pulses as simulated in Fig. 9. Initially, with the normal loading of the battery is considered, with all the battery modules were discharging at the same rate (8A). The power losses were $4 \mathrm{~W}$ for modules 1 and 3 but for module 2 , the power loss was $5 \mathrm{~W}$.

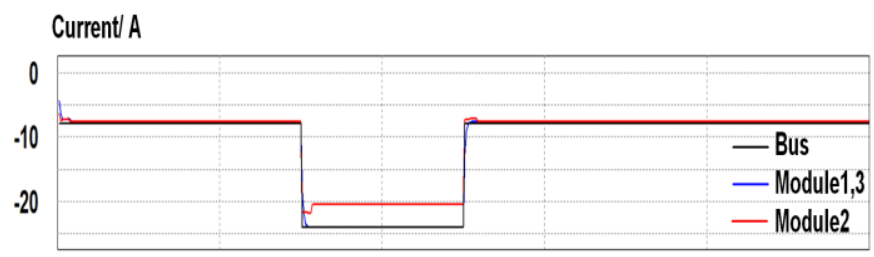

\section{Power losses/W}
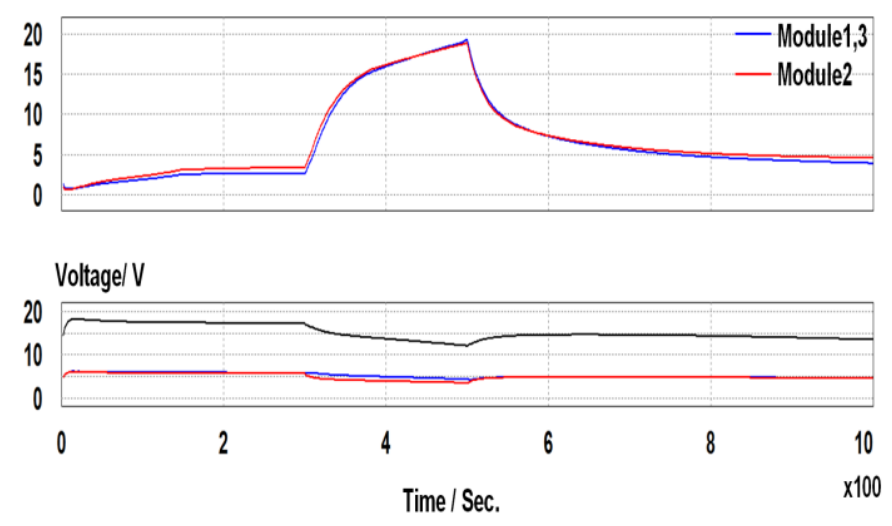

Fig. 9: Balance of power losses (step-down mode)
During the peak power pulse (i.e. load demand that started at $\mathrm{t}=300 \mathrm{~s}$ ), in order to keep thermal balance between the cells, the system controller decreased the power share of module 2 by setting its current to be $20 \mathrm{~A}$ whilst maximizing the power contribution of the other modules ( 1 and 3 ) by setting their current to be same as $\mathrm{I}_{\text {bus }}$ (i.e. 24A).

In this way, the effect of increased impedance in power losses in module 2 has been cancelled by decreasing the power contribution of this module. The power loss for all modules approached $20 \mathrm{~W}$ maximum during the pulse which is better than the TCB system where cell 6 power losses reached $25 \mathrm{~W}$ for the same load (Fig. 7). Once the peak pulse loading finished at $\mathrm{t}=500 \mathrm{~s}$, the controller sets the current for all modules to be the same again as the load power has been reduced and the power loss reduced accordingly. It can also be seen, that for the module with lower current sharing, the converter output voltage is less and the overall bus voltage decreases which can be considered as one of the disadvantages of the step-down topology.

Fault tolerance also can be achieved with the MBS with stepdown topology by bypassing the module that has a faulty cell as simulated in Fig. 10.

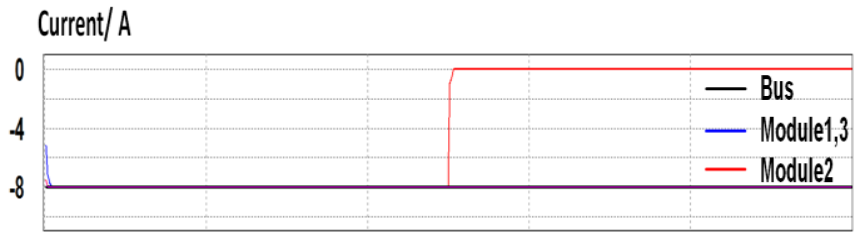

\section{Voltage/V}
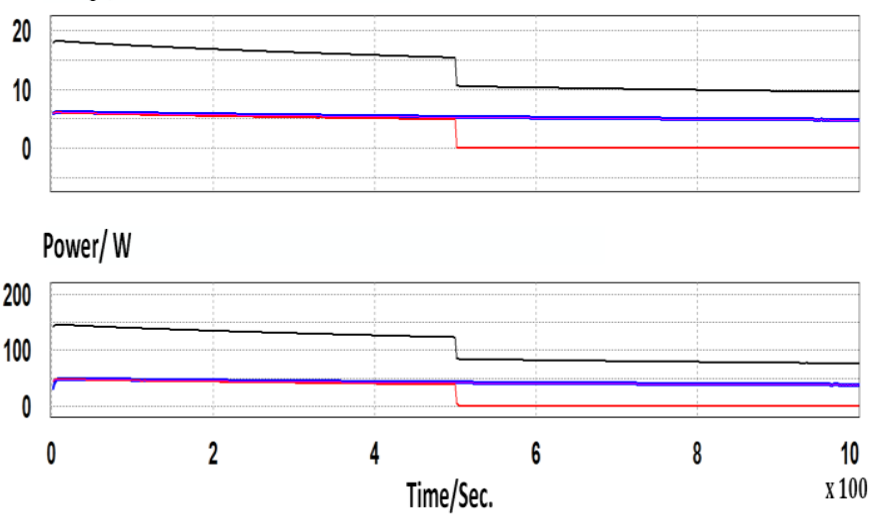

Fig. 10: Bypassing of faulty module (step-down mode)

The system controller bypassed module 2 due to a risk of fault to one of its cells at $(\mathrm{t}=500 \mathrm{~s})$, whilst other modules $(1,3)$ still provide their power. However the bus voltage has been decreased (from $15 \mathrm{~V}$ to $10 \mathrm{~V}$ ) due to the loss of module 2 voltage, which cannot be compensated by the other modules ( 1 and 3) due to step-down topology that limits the maximum module voltage contribution to the string to $\mathrm{V}_{\text {batt. }}$.

With the step-up MBS topology, the cells capacity imbalances balancing can be processed by providing more power to modules with higher capacities by controlling the module 
currents so that all battery modules reach their full SoC at the same time. This situation can be seen in Fig.11. During the charging process, the controller sets the current of module 2 to $8 \mathrm{~A}$ as its capacity is $10 \%$ lower compared to the other modules ( 1 and 3 ) that have their currents set to 12A. All modules have reached $100 \%$ SoC at the same time at $\mathrm{t}=1100 \mathrm{~s}$. This technique also removed the need for pausing the charging process to do balancing, as needed by the TCB system.

\section{Current/A}

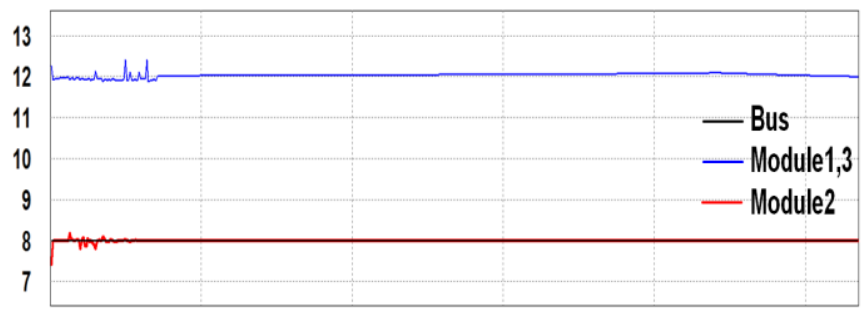

SoC $\%$

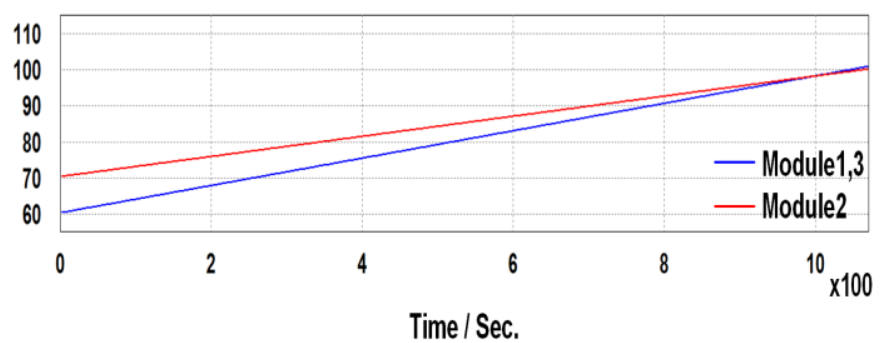

Fig.11: Charging process with MBS step-up mode

Thermal balancing cannot be done effectively by boost mode as the current for any of the modules cannot go below the bus current which is the load current (Fig. 12).

\section{Current/A}

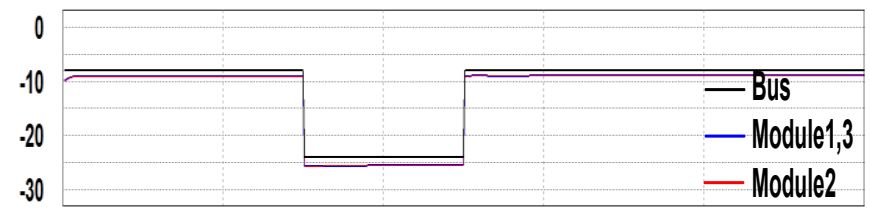

\section{Power losses/W}

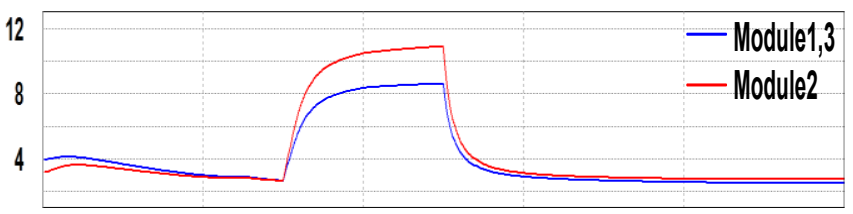

\section{Voltage/V}

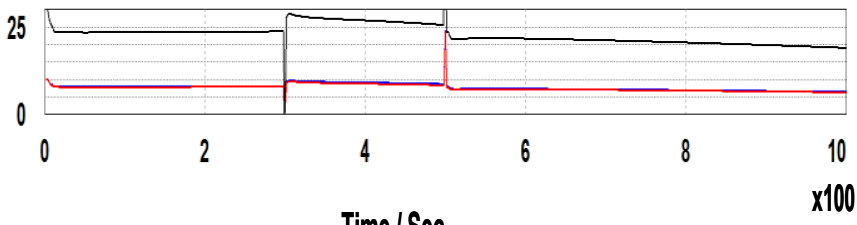

Time / Sec.

Fig. 12: Power losses imbalance for string cells (step-up mode)
Instead, a module which may have a cell under the risk of thermal runaway under the a specific bus current can be bypassed (by means of additional separation switch as explained in II.B, and the required power from it can be loaded onto other modules according to their SoH. On the other hand, the step-up topology can maintain the bus voltage as the bypassed module voltage can be compensated by boost up the voltages produced by other modules, which is an advantage compared to the step-down topology. This is because the battery current in boost topology can exceed $\mathrm{I}_{\text {bus }}$ and module voltage can exceed $V_{\text {batt }}$.

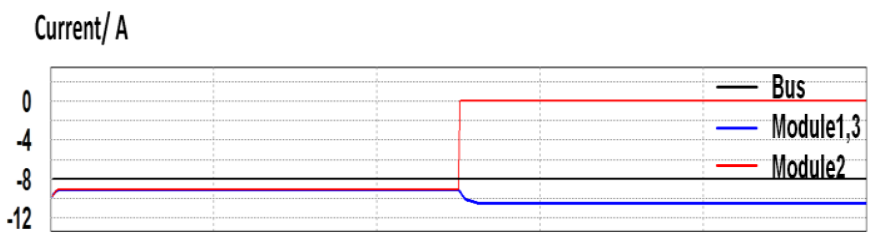

Voltage/ V
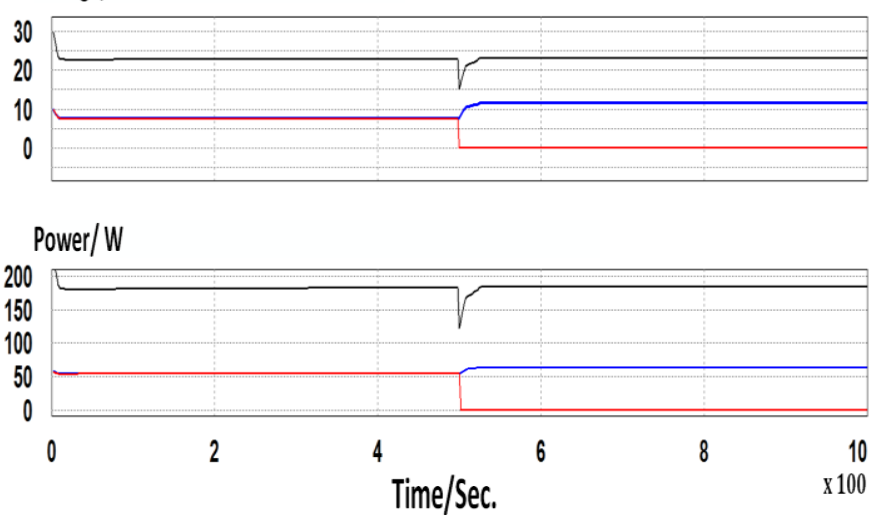

Fig. 13: Bypassing of faulty module (step-up mode)

Fault tolerance also can be achieved with step up topology by bypassing the module that has a faulty cell or a cell under the risk of reaching critical limit as simulated in Fig. 13. The system controller bypassed by doing a maneuver described in section II.B module 2 due to an assumed risk of over discharge to one of its cells at $(\mathrm{t}=500 \mathrm{~s})$. Before this time, all modules were discharging with the same current and each module provided around $7.7 \mathrm{~V}$ to the bus voltage resulting in the overall bus voltage to be around $23 \mathrm{~V}$. At $(\mathrm{t}=500 \mathrm{~s})$ as module 2 has been bypassed, its voltage contribution to the bus dropped to zero, however module 1 and module 3 stepped up their output voltage to $11.5 \mathrm{~V}$ to compensate for loosing module 2 voltage keeping bus voltage maintained constant. 


\section{CONCLUSION}

This paper has investigated the benefits of using a modular battery system with cascaded converters to implement energy balancing functionality between mismatched battery cells. This method provided more capabilities for energy management of the battery compared to traditional centralized battery system. It also can implement a new concept of balancing the thermal stress of the battery cells. The use of two interchangeable stepup and step-down converter topologies has been investigated for the cascaded topology: both topologies provided effective balancing of the energy among cells. However, the step-up topology could only provide partial thermal stress balancing. The step-up topology could maintain a fixed bus voltage when a fault happens to one of the modules, by bypassing the faulty modules but they require an additional reverse conductive solid state or a mechanical switch (and incurring the associated conduction losses in series with the battery) and transfer the load to the other healthy modules. However the step-down topology can fully bypass the faulty module without any additional hardware but additional redundant modules are needed to compensate for the loss of voltage if the bus voltage is needed to be kept constant (more cells of lower capacity in terms of Ah would be needed which does not necessarily means a higher amount of energy stored in terms of Wh).

\section{ACKNOWLEDGMENT}

This work was supported by the Egyptian Government through a PhD scholarship sponsored by Ministry of Higher Education (Cultural Affairs and Missions Sector).

\section{REFERENCES}

[1] R. Gogoana, M. B. Pinson, M. Z. Bazant, and S. E. Sarma, "Internal resistance matching for parallel-connected lithium-ion cells and impacts on battery pack cycle life," Journal of Power Sources, vol. 252, pp. 8-13, 4/15/ 2014.

[2] J. Cao, N. Schofield, and A. Emadi, "Battery balancing methods: A comprehensive review," in 2008 IEEE Vehicle Power and Propulsion Conference, 2008, pp. 1-6.

[3] N. H. Kutkut, H. L. N. Wiegman, D. M. Divan, and D. W. Novotny, "Charge equalization for an electric vehicle battery system," IEEE Transactions on Aerospace and Electronic Systems, vol. 34, pp. 235 246, 1998

[4] M. Daowd, N. Omar, P. V. D. Bossche, and J. V. Mierlo, "Passive and active battery balancing comparison based on MATLAB simulation," in 2011 IEEE Vehicle Power and Propulsion Conference, 2011, pp. 1-7.

[5] S. Wen, "Cell balancing buys extra run time and battery life," Analog Applications Journal, vol. 1Q, 20092009.

[6] T. Instruments, "PowerLANTM Master Gateway Battery Management Controller With PowerPump ${ }^{\mathrm{TM}}$ Cell Balancing Technology," ed, 2008.

[7] L. Lu, X. Han, J. Li, J. Hua, and M. Ouyang, "A review on the key issues for lithium-ion battery management in electric vehicles," Journal of Power Sources, vol. 226, pp. 272-288, 3/15/ 2013.

[8] L. R. Yu, Y. C. Hsieh, W. C. Liu, and C. S. Moo, "Balanced discharging for serial battery power modules with boost converters," in 2013 International Conference on System Science and Engineering (ICSSE), 2013, pp. 449-453.

[9] W. Hong, K. S. Ng, J. H. Hu, and C. S. Moo, "Charge equalization of battery power modules in series," in The 2010 International Power Electronics Conference - ECCE ASIA -, 2010, pp. 1568-1572.

[10] L. R. Yu, D. Ye, and C. S. Moo, "Discharging scenario of serial buckboost battery power modules with fault tolerance," in IECON 2015 - 41st Annual Conference of the IEEE Industrial Electronics Society, 2015, pp. 001622-001626.

[11] Y. Li and Y. Han, "A Module-Integrated Distributed Battery Energy Storage and Management System," IEEE Transactions on Power Electronics, vol. 31, pp. 8260-8270, 2016.

[12] N. Mukherjee and D. Strickland, "Analysis and Comparative Study of Different Converter Modes in Modular Second-Life Hybrid Battery Energy Storage Systems," IEEE Journal of Emerging and Selected Topics in Power Electronics, vol. 4, pp. 547-563, 2016.

[13] A. M. Fares, C. Klumpner, and M. Sumner, "Development of a battery energy loss observer based on improved equivalent circuit modelling," in 2016 18th European Conference on Power Electronics and Applications (EPE'16 ECCE Europe), 2016, pp. 1-10. 